\title{
KONSEKUENSI TANGGUNG JAWAB DALAM PEMBELAJARAN MATEMATIKA SMA
}

\author{
Sabar Narimo, Desi Dwi Hastuti, dan Anam Sutopo \\ Magister Administrasi Pendidikan Sekolah Pascasarjana \\ Universitas Muhammadiyah Surakarta \\ Email: desidwi80@gmail.com
}

\begin{abstract}
This study aims to describe the consequences of student responsibility in learning mathematics in high school. This research is a qualitative research with ethnography design. Techniques of collecting data using interviews, observation, and documentation. Data analysis techniques use interactive model analysis. The results of this study: 1) students can help himself that is not unyielding in doing many tasks and difficult. Students who have completed the task are sure to have good grades in the report card so that will help him enroll in State College through SNMPTN. Neat student records help themselves in learning whether it is repeating the material or doing the task. 2) efficient students help others is doing their own work without the help of others. This means that if students do not interfere with his friends then his friends can work or learn without any disturbing so as to improve his achievement. 3) students can be trusted to do the tasks and mandate that charged well. In the teacher's note Counseling Guidance there are students who feel unbelievable that it needs special handling until the psychiatrist is called. With the help of BK teacher, Wakasek Kesiswaan, and Guardian Class the problem can be resolved. Students who give mandate as chairman of the class or chairman of the organization must be able to carry out their duties with responsibility to be trusted.
\end{abstract}

Keywords: consequence, responsibility, learning, math

Abstrak. Penelitian ini bertujuan untuk mendeskripsikan konsekuensi tanggung jawab siswa dalam pembelajaran matematika di SMA. Penelitian ini merupakan penelitian kualitatif dengan desain etnografi. Teknik pengumpulan data menggunakan wawancara, observasi, dan dokumentasi. Teknik analisis data menggunakan analisis model interaktif. Hasil penelitian ini: 1) siswa dapat membantu dirinya sendiri yaitu tidak pantang menyerah dalam mengerjakan tugas yang banyak dan sulit. Siswa yang sudah melengkapi tugas dipastikan mempunyai nilai yang baik di raport sehingga akan membantu dirinya mendaftar di Perguruan Tinggi Negeri lewat jalur SNMPTN. Catatan siswa yang rapi membantu dirinya sendiri dalam belajar baik itu mengulang materi atau mengerjakan tugas. 2) siswa efisien membantu orang lain yaitu mengerjakan tugas sendiri tanpa bantuan orang lain. Artinya jika siswa tidak mengganggu temannya maka temannya bisa mengerjakan atau belajar tanpa ada yang mengganggu sehingga dapat meningkatkan prestasinya. 3) siswa dapat dipercaya mengerjakan tugas dan amanah yang dibebankan dengan baik. Dalam catatan guru Bimbingan Konseling ada siswa yang merasa tidak dapat dipercaya sehingga perlu penanganan khusus sampai dipanggilkan psikiater. Dengan bantuan guru BK, Wakasek Kesiswaan, dan Wali Kelas masalah tersebut bisa teratasi. Siswa yang beri amanah sebagai ketua kelas atau ketua organisasi harus dapat melaksanakan tugasnya dengan tanggung jawab agar dapat dipercaya.

Kata kunci: konsekuensi, tanggung jawab, pembelajaran, matematika 


\section{Pendahuluan}

Tanggungjawabdapatdiwujudkanmelalui pelatihan yang intensif sejak kecil melalui pengalaman, pembiasaan, dan praktek seharihari secara disiplin. Tanggung jawab harus melalui hukuman apabila tidak dilaksanakan sehingga orang tidak mudah melepas tanggung jawab. Sejak kecil penting untuk berlatih tanggung jawab bagaimana menyediakan keperluan diri untuk mengerjakan pekerjaan rumah dan melaksanakan setiap tugas yang menjadi kewajiban. Masalah dalam kehidupan manusia sering terjadi karena melepas tanggung jawab yang dibebankan kepadanya. Dalam kehidupan pribadi, tanggung jawab menyangkut tugas dan kewajiban yang harus dilaksanakan dalam hidup individu yang bersangkutan seperti seorang siswa harus belajar agar dirinya berhasil.

SMA Negeri 1 Surakarta merupakan sekolah favorit di kota Surakarta. Banyak prestasi yang diperoleh dari sekolah ini baik prestasi siswa maupun prestasi guru. Prestasi tersebut adalah prestasi akademik dan non akademik. Untuk prestasi akademik, siswa SMA Negeri 1 Surakarta selalu mendapatkan nilai rata-rata ujian nasional yang baik, siswa SMANegeri 1 Surakarta banyak yang diterima di Perguruan Tinggi Negeri melalui jalur SNMPTN, jalur PMDK, dan jalur SBMPTN. Hal ini yang membuktikan bahwa SMA Negeri 1 Surakarta sudah dipercaya kualitasnya oleh Perguruan Tinggi Negeri sehingga setiap tahun pasti dapat jatah kursi bagi siswa yang nilai raportnya bagus. Banyak juga siswa SMA Negeri 1 Surakarta yang melanjutkan pendidikannya di luar negeri seperti Amerika, Jerman, Jepang, dan Singapura.

Untuk bidang non akademik ada siswa SMA Negeri 1 Surakarta yang menjadi peserta paskibra tingkat propinsi tahun 2017 dan masih banyak yang menjadi pemenang diberbagai jenis lomba seperti lomba karya tulis ilmiah tingkat Nasional. Sedangkan prestasi guru seperti guru berprestasi tingkat kota, pemenang lomba olimpiade guru, dan ada guru yang pernah menjadi ketua panitia
ASEAN Paragames Non Akademik 2011 ASEAN OCEAN I A Internasional.

Prestasi yang diraih SMA Negeri 1 Surakarta selama ini tidak didapat dengan mudah. Selain berdoa, belajar dan berlatih, perlu penanaman sikap anti korupsi karakter tanggung jawab. Siswa yang bertanggung jawab pasti berusaha untuk mengerjakan tugas dengan baik, dan menepati janji untuk menjadi juara, sehingga siswa dapat dipercaya untuk mengikuti lomba lagi. Banyak lulusan SMA Negeri 1 Surakarta yang menjadi pimpinan atau tokoh penting masyarakat yang bertanggung jawab yaitu dapat merasakan kesulitan orang lain. Sebagai contoh dari alumni yang sudah sukses itu tidak segan-segan memberikan program beasiswa KASMAJI (Bekas SMA Siji) kepada adik tingkat yang berprestasi dan kurang mampu dengan biaya sekolah gratis. Beasiswa KASMAJI tersebut juga berlaku bagi alumni SMA Negeri 1 Surakarta yang ingin melanjutkan kuliah di Institut Pertanian Bogor (IPB) dengan biaya gratis.

Berbagai prestasi yang diraih SMANegeri 1 Surakarta baik siswa maupun guru tersebut menjadikan sekolah ini sebagai "incaran" orang tua untuk menyekolahkan anaknya di SMA Negeri 1 Surakarta. Oleh karena itu, semua warga SMA Negeri 1 Surakarta merasa tertantang bagaimana mempertahankan kepercayaan masyarakat ini. Semakin favorit SMA Negeri 1 Surakarta di mata masyarakat semakin besar tanggung jawab sekolah ini dalam mempertahankan kefavoritannya.

Dalam pembelajaran matematika, diharapkan siswa dapat melakukan hal-hal yang baik. Membentuk karakter yang baik akan jauh lebih mudah jika dilakukan di lingkungan yang memiliki tanggung jawab moral yang tinggi.

Agar pembelajaran matematika dapat berhasil sesuai yang diharapkan, guru bertanggung jawab atas proses belajar siswa dengan mengatur dan mengkondisikan lingkungan belajar dimana guru secara aktif dan inovatif mendukung siswa dalam pembelajaran matematika, dan siswa juga 
aktif sendiri dalam belajar matematika. Dalam kondisi siswa yang bagaimanapun, baik itu siswa dari keluarga kaya atau miskin dan pintar atau tidak pintar, guru bertanggung jawab dalam kesuksesan pembelajaran. Pembelajaran matematika dapat mendorong interaksi dan pemecahan masalah yang disesuaikan dengan siswa, sehingga siswa dapat membangun tanggung jawab untuk belajar.

Tujuan dari penelitian ini untuk mendeskripsikan konsekuensi tanggung jawab siswa dalam pembelajaran matematika di SMA Negeri 1 Surakarta. Konsekuensi mengerjakan tanggung jawab mempunyai beberapa keuntungan seperti dapat membantu dirinya sendiri, efektif dalam membantu orang lain, dan dapat dipercaya. Sebaliknya, konsekuensi tidak mengerjakan tanggung jawab mempunyai beberapa kerugian seperti melahirkan kegagalan dan melahirkan lemah mental.

Kajian teori yang digunakan dalam penelitian ini adalah tanggung jawab. Thomas Lickona (1992) mendefinisikan tanggung jawab adalah melaksanakan sebuah pekerjaan atau kewajiban dalam keluarga, di sekolah, maupun di tempat bekerja dengan sepenuh hati dan memberikan yang terbaik. Sikap tanggung jawab ditekankan pada mengutamakan hal-hal yang hari ini dianggap penting sebagai suatu perbaikan di masa yang akan datang dengan didasari hak-hak.

\section{Metode Penelitian}

Metode dalam penelitian ini adalah metode kualitatif dengan desain etnografi. Tempat penelitian adalah di SMA Negeri 1 Surakarta yang dilakukan mulai bulan Januari 2018 sampai bulan Juni 2018.

Data yang diperoleh dari narasumber adalah informasi yang diberikan Kepala Sekolah, Wakil Kepala Bidang Kesiswaan, Guru Bimbingan Konseling, Guru Matematika, dan siswa. Teknik pengumpulan data ini digunakan teknik wawancara, observasi, dan dokumentasi. Keabsahan data menggunakan teknik triangulasi sumber dan metode.
Teknik analisis data ini menggunakan analisis model interaktif. Bogdan dan Biklen (dalam Dzama"an Satori (2014: 200) mengemukakan bahwa analisis data kualitatif adalah upaya yang dilakukan dengan jalan bekerja dengan data, mengorganisasikan data, memilah milahnya menjadi satuan yang dapat dikelola, mensintesiskannya, mencari, dan menemukan pola, menemukan apa yang penting dan apa yang dipelajari dan memutuskan apa yang dapat diceritakan kepada orang lain, masing-masing makna diuraikan sebagai berikut: reduksi, penyajian, dan kesimpulan.

\section{Hasil dan Pembahasan}

Konsekuensi mengerjakan tanggung jawab diantaranya membantu diri sendiri, efektif membantu orang lain, dan dapat dipercaya. Berikut diskusi uraian tentang membantu diri sendiri, efektif membantu orang lain, dan dapat dipercaya.

\section{Membantu diri sendiri}

Pada dasarnya seorang yang telah diberi tugas berarti mengalami pembelajaran. Seorang yang bertanggung jawab akan berusaha menyelesaikan tugas tersebut. Ini berarti melatih seorang dalam mencapai kesuksesan. Seorang yang menunda pekerjaan berarti tugasnya akan semakin menumpuk dan lama dalam menyelesaikannya. Ini berarti dalam mencapai kesuksesan juga semakin lama.

Penanaman karakteristik tanggung jawab siswa akan membantu diri sendiri dalam meraih keberhasilan di masa mendatang. Konsekuensi mengerjakan tanggung jawab dapat membantu diri sendiri. Pada saat siswa mengerjakan tugas sendiri secara otomatis siswa belajar untuk mengulang materi matematika yang belum dipahami. Dengan demikian, penanaman pendidikan anti korupsi karakter tanggung jawab dapat meningkatkan prestasi belajar siswa terutama pada mata pelajaran matematika.

Siswa dapat membantu dirinya sendiri diantaranya tidak pantang menyerah dalam 
mengerjakan tugas yang banyak dan sulit. Di RPP terdapat lembar penilaian tugas baik tugas terstruktur maupun tugas non terstruktur. Siswa yang sudah melengkapi tugas dipastikan mempunyai nilai yang baik di raport sehingga akan membantu dirinya sendiri ketika mendaftar di Perguruan Tinggi Negeri lewat jalur SNMPTN. Catatan siswa yang rapi akan membantu dirinya sendiri dalam belajar baik itu mengulang materi atau mengerjakan tugas. Menurut pendapat Jagger (2014) menyatakan pendekatan holistik untuk mengajar diperlukan, di mana siswa didorong untuk mengembangkan pengetahuan dan keterampilan untuk nilai pribadi mereka. Ini bermakna semakin banyak siswa berinvestasi dalam proses belajar mereka sendiri, semakin banyak mereka belajar. Hal ini akan meningkatkan prestasi belajar matematika.

\section{Efektif membantu orang lain}

Ketika seseorang sudah mampu mengerjakan semua tugas yang diberikan berarti ia tidak perlu bantuan orang lain dalam menyelesaikan tugas. Jika suatu pekerjaan bisa dikerjakan satu orang mengapa harus dikerjakan dua orang atau lebih.

Penanaman karakteristik tanggung jawab siswa akan membantu orang lain secara efektif. Orang yang bertanggung jawab akan dapat mengefisienkan tenaga dan waktu secara tepat. Pendidikan anti korupsi karakter tanggung jawab perlu disisipkan pada mata pelajaran matematika karena menjadikan siswa lebih efektif membantu orang lain.

Efisien membantu orang lain diantaranya siswa mengerjakan tugas sendiri tanpa bantuan orang lain. Artinya jika siswa itu tidak mengganggu temannya maka temannya bisa mengerjakan ataubelajar sendiri tanpa ada yang mengganggu sehingga ia dapat meningkatkan nilainya atau prestasinya. Menurut pendapat Crisan (2013) menyatakan keuntungan besar yang ditawarkan oleh penggunaan proyek kolaboratif dengan mengorganisasikan ruang kelas virtual, diwakili dengan membuka stok sumber daya media interaktif yang tersedia secara global. Ini bermakna lingkungan belajar dan eksplorasi yang lebih berpusat pada siswa, di mana guru mengambil peran lain selain penyedia informasi tunggal akan memudahkan siswa dalam belajar sehingga mengurangi ketergantungan dengan orang lain dalam belajar.

\section{Dapat dipercaya}

Tanggung jawab akan melahirkan kepercayaan. Jika seorang diberi tugas dan tidak mengerjakannya dengan baik maka seorang tersebut akan dikatakan tidak mempunyai tanggung jawab.

Penanaman karakteristik tanggung jawab dapat melahirkan kepercayaan. Embanlah setiap jabatan yang dipegang dengan baik. Tidak ada bedanya memegang jabatan ketua OSIS ataupun ketua kelas. Keduanya sama-sama jabatan tertinggi yang harus dilaksanakan dengan baik. Memegang salah satu dari jabatan ini berarti sudah dipercaya untuk melaksanakan amanah. Karena sudah diberi amanah seorang harus bertangung jawab melaksanakan tugas dengan baik dan jujur. Penanaman karakter tanggung jawab pada pendidikan anti korupsi perlu disisipkan pada pembelajaran matematika karena siswa lebih bisa dipercaya dan akhirnya bisa meningkatkan hasil belajar siswa pada mata pelajaran matematika.

Siswa SMA Negeri 1 Surakarta dapat dipercaya mengerjakan tugas dan amanah yang dibebankan dengan baik. Dalam catatan guru Bimbingan Konseling ada siswa yang perlu penanganan khusus sampai dipanggilkan psikiater. Dengan bantuan guru BK, Wakasek Bidang Kesiswaan, dan Wali Kelas masalah tersebut bisa teratasi. Siswa yang beri amanah sebagai ketua kelas atau ketua organisasi harus dapat melaksanakan tugasnya dengan tanggung jawab. Dengan demikian, siswa merasa dapat dipercaya lagibaik teman maupun guru. Menurut Simacheva (2016) menyatakan bahwa siswa yang memiliki tingkat aktivitas inovatif yang berbeda akan menunjukkan tingkat kepercayaan yang berbeda-beda. Ini maknanya siswa yang bertanggung jawab akan dipercaya dalam melaksanakan tugas 
dan amanah yang diberikan kepadanya. Sebaliknya, siswa yang tidak tanggung jawab tidak akan dipercaya dan tidak akan diberi amanah.

\section{Penutup}

Konsekuensi mengerjakan tanggung jawab siswa dalam pembelajaran matematika di SMA Negeri 1 Surakarta tahun pelajaran 2017/2018 mempunyai beberapa keuntungan seperti dapat membantu dirinya sendiri, efektif dalam membantu orang lain, dan dapat dipercaya. Sebaliknya, konsekuensi tidak mengerjakan tanggung jawab mempunyai beberapa kerugian seperti melahirkan kegagalan dan melahirkan lemah mental. Pembelajaran kooperatif atau metode lain yang melibatkan semua siswa telah diterapkan guru matematika di SMA Negeri 1 Surakarta. Hal ini dilakukan untuk meningkatkan interaksi di antar siswa dan saling membantu dalam menyelesaikan tugas yang diberikan guru. Dengan guru melibatkan tanggung jawab siswa dalam pembelajaran matematika akan menghindari rasa cemas, takut gagal, dan kurang minat dalam pembelajaran matematika.

Berbagai ucapan terima kasih kami sampaikan kepada berbagai pihak yang telah mendukung kegiatan penelitian ini. Ucapan terima kasih kami sampaikan kepada Direktorat Riset dan Pengabdian Masyarakat Direktorat Jenderal penguatan Riset dan Pengembangan Kementerian Riset, Teknologi, dan Pendidikan Tinggi yang telah membantu dalam pendanaan biaya penelitian multi tahun melalui Hibah Penelitian Tim Pascasarjana. Ucapan terima kasih kami sampaikan kepada Direktur Sekolah Pascasarjana dan Ketua Lembaga Penelitian UMS beserta stafnya, yang telah memberikan fasilitas dan dorongan sehingga kami bisa melakukan penelitian. Ucapan terima kasih juga kami sampaikan kepada kepala Dinas Pendidikan, kepala dan guru matematika SMA Negeri 1 Surakarta, yang telah membantu proses penelitian sehingga berjalan sesuai perencanaan.

\section{Daftar Pustaka}

Bacon, C. (1990). Response-Ability. American Secondary Education, 18(2), 15-18. Retrieved from http://www.jstor.org/stable/41063912

Bruner, J. (1960). On learning mathematics. The Mathematics Teacher, 53(8), 610-619. Retrieved from http://www.jstor.org/stable/27956266

Crisan, A. (2013). Virtual Classrooms in Collaborative Projectsand The effectiveness of The Learning Process. 76, 226-232. Retrieved from www.sciencedirect.com

Drew, P., Robert, A., Martin, C., \& Mraz, M. (2015). Perceptions of The Roles and Responsibilities of Elementary School Mathematics Coaches. 2, 126-141. Retrieved from www.emeraldinsight.com/2046-6854.htm

Fagimovich, I. (2014). Development Of Student'Civil Responsibility In The Process Of Social Projecting. 191, 801-804. Retrieved from www.sciencedirect.com

Fingarette, H. (1966). Responsibility. Mind, 75(297), new series, 58-74. Retrieved from http:// www.jstor.org/stable/2251710

Hamzah, A. (2014). Perencanaan dan Strategi Pembelajaran Matematika. (1). Jakarta: PT Rajagrafindo Persada

Hansson, Å. (2010). Instructional responsibility in mathematics education: Modelling classroom teaching using Swedish data. Educational Studies in Mathematics, 75(2), 171-189. Retrieved from http://www.jstor.org/stable/40928554

Hansson, A. (2012). The meaning of mathematics instruction in multilingual classrooms: 
Analyzing the importance of responsibility for learning. Educational Studies in Mathematics, 81(1), 103-125. Retrieved from http://www.jstor.org/stable/23254221

Karp, K., \& Howell, P. (2004). Building Responsibility for Learning in Students with Special Needs. Teaching Children Mathematics, 11(3), 118-126. Retrieved from http://www.jstor. org/stable/41198461

Lee (1997). How High School Organization Influences the Equitable Distribution of learning in Mathematics and Science. 70(2), 128. ProQuest Document Link.

Lickona, T. (2013). Educating For Character. (2). Jakarta: Bumi Aksara

Matteucci. (2018). Who is Responsible for Educational Outcomes? Responsibility Ascriptions for Educational Outcomes in A Sample of Italian Teacher, Parents, and Students. 10. Retrieved from www.elsevier.com/locate/lindif

Meaney, T., \& Evans, D. (2013). What is the responsibility of mathematics education to the Indigenous students that it serves? Educational Studies in Mathematics, 82(3), 481-496. Retrieved from http://www.jstor.org/stable/23434474

Nashir H. (2013). Pendidikan Karakter Berbasis Agama dan Budaya. (1). Yogyakarta: Multi Presindo

Niculescu, R. (2013). Human Resources as Leading and Supporting Actors of a Curriculum Reform. 81, 122-125. Retrieved from www.sciencedirect.com

Niculescu, R. (2013). Religious Education an Important Dimension of Human Education. 93, 338-342. Retrieved from www.sciencedirect.com

Odafe, Victor U (1998). Students Generating Tes Items: A Teaching and Assessment Strategy, 91(3), 198-202. ProQuest Document Link.

Orlove, B., Lazrus, H. Hovelsrud, G. \& Giannini, A. (2014). Recognition and Responsibilities, 55(3), 249-275. Retrieved from http://www.jstor.org/stable/10.1086/676298.

Pendergrass, R. (1982). A "Thinking" Approach to Teaching Responsibility. The Clearing House, 56(2), 90-92. Retrieved from http://www.jstor.org/stable/30186162

Spencer, M., Dupree, D., \& Swanson, D. (1996). Parental Monitoring and Adolescents'Sense of Responsibility for Their Own Learning: An Examination of Sex Differences. The Journal of Negro Education, 65(1), 30-43. doi:10.2307/2967366

Simacheva (2016). Trust Development in One's Self and in Others of University Students Engaged in Innovative Activity, 36, 15-17. Procedia-Social and Behavioral Sciences

Spivak, G. (1994). Responsibility. Boundary 2, 21(3), 19-64. doi:10.2307/303600

Subur. (2015). Pembelajaran Nilai Moral dan Berbasis Kisah. (1). Yogyakarta: Kalimedia

Sugiono. (2010). Metode Penelitian Bisnis. (15). Bandung: Alfabeta

Sumardjoko. (2015). Metodologi Penelitian Kualitatif. (1). Surakarta: Universitas Muhammadiyah Surakarta.

Sutama. (2016). Metode Penelitian Pendidikan. (2). Surakarta: Fairuz Media.

Zahra, T., Amineh A., \& Maryam M. (2015). The Effect of m-Learning on Mathematics Learning, 171, 83-89. Procedia-Social and Behavioral Sciences.

. Pendidikan Anti Korupsi SMA/MA Kelas X.

. Pendidikan Anti Korupsi SMP/MTS Kelas VII. 